\title{
UMA ANÁLISE DO COMPORTAMENTO EMPREENDEDOR E DO PROCESSO DECISIONAL DE PRESIDENTES DE ASSOCIAÇÕES APÍCOLAS NO RIO GRANDE DO SUL
}

\author{
An entrepreneurial behavior and \\ decisional process analyses of presidents of \\ beekeeping associations in Rio Grande do Sul
}

Leticia Lengler ${ }^{1}$

\section{Resumo}

Este estudo propõe-se a relacionar o perfil empreendedor e o processo de tomada de decisão de produtores rurais em organizações coletivas. Objetiva-se, assim, identificar o processo decisório e o comportamento empreendedor dos presidentes de duas associações apícolas localizadas na Região Central do Rio Grande do Sul. Para responder esses objetivos, a pesquisa utilizou-se de informações provenientes de questionários divididos em duas partes, uma sobre processo decisório e outra sobre o perfil empreendedor, aplicados aos dois presidentes das associações em questão. Dessa forma, foi possível identificar que os dois presidentes das associações demonstram potencial empreendedor, no entanto, um deles toma decisões mais individualmente do que coletivamente.

Palavras-chave: Tomada de Decisão; Empreendedorismo; Associações Apícolas.

\begin{abstract}
This study purposes to relate the entrepreneurial profile and the decision making process of rural producers in collective organizations. Therefore, it's aimed to identify the decisional process and the entrepreneurial profile of the presidents of two beekeeping associations located
\end{abstract}


in the central area of Rio Grande do Sul. To reach these goals, the research used information from the two presidents through a two part questionnaire, one part regarding the decisional process and the other regarding the entrepreneurial profile. This way, it was possible to identify that the two presidents showed an entrepreneurial potential, however one of them takes decisions more individually them collectively.

Keywords: Decision Making; Entrepreneurship; Beekeeping Associations.

\section{Introdução}

A criação e o desenvolvimento de pequenas organizações de produtores são estratégias simples, capazes de contribuir para a geração de empregos, para o desenvolvimento e crescimento econômico regional. Contudo, devido às altas taxas de mortalidade dessas organizações, faz-se necessário que sua gestão torne-se, cada vez mais, empreendedora, no sentido de buscar alternativas para a sua sobrevivência e sustentabilidade no mercado.

O empreendedorismo é destacado por diversos autores, como Schumpeter (1950), McClelland (1972), entre outros, como um dos principais fomentadores do desenvolvimento econômico de um país. Partindo dessas considerações, acredita-se que a presença do empreendedorismo em todas as organizações de produtores é uma característica desejável. Porém, isto nem sempre ocorre, o que acarreta uma menor participação dessas organizações no mercado, influenciando diretamente o desenvolvimento e crescimento econômico.

Diante desse contexto, torna-se estratégico estabelecer relações coletivas que possam viabilizar iniciativas que, individualmente, têm dificuldades de obter sucesso. Nesse âmbito, ressalta-se, dentre as diferentes formas de organizações coletivas, as associações, empreendimentos estes que visam a atingir objetivos comuns, os quais dificilmente seriam alcançados por empreendedores individuais.

Entretanto, sempre que houver mais de um indivíduo envolvido no processo decisório, a situação aumenta em complexidade, como no caso das associações, nas quais as necessidades e objetivos não apenas de um indivíduo, mas de todo o grupo devem ser consideradas durante o processo decisório.

Assim apresenta-se, como objeto de análise deste estudo, duas associações apícolas da Região Central do Rio Grande do Sul (RS), uma vez que as decisões tomadas por seus presidentes, além de influenciadas pela sua percepção acerca do ambiente e pelas suas características comportamentais, sofrem também a influência dos interesses individuais dos demais associados.

Tal constatação aponta para a necessidade de se realizar um estudo cujo objetivo é caracterizar o comportamento empreendedor dos presidentes de duas associações apícolas do RS, bem como identificar o seu processo decisório.

O estudo se justifica pela carência de estudos e pesquisas que retratem a questão da tomada de decisão no associativismo. Além do que, é acrescentada a esta variável a relação com os aspectos comportamentais de seus empreendedores.

\section{Processo decisório}

Os indivíduos e as organizações se defrontam, a cada momento, com um grande número de alternativas de comportamento, algumas das quais são conscientes. Conforme 
Simon (1965), o processo de decisão ou escolha se constitui pela seleção e realização de uma dessas alternativas. Acrescenta-se, ainda, que o conjunto dessas decisões que determinam o comportamento, em um dado período de tempo, chama-se estratégia.

Para se definir a estratégia empresarial é importante a compreensão do gap entre as pretensões dos dirigentes e as reais possibilidades da empresa, ou seja, entender a combinação da análise do ambiente (externa) e da análise interna, proposta originalmente por Andrews (1971) torna-se necessário para nortear as decisões.

Independentemente do porte da empresa, a tomada de decisão é o ponto básico da atividade administrativa e da gestão das organizações. Como afirmam Becker et al. (1997), esta atividade acontece todo o tempo, em todos os níveis, e influencia diretamente o desempenho de uma organização.

A primeira abordagem para o processo de tomada de decisão foi a do modelo racional. Nesse modelo, o indivíduo da organização ainda possui como características apenas as contempladas pela administração científica, ou seja, o tipo ideal representado pelo homus economicus, herdado da economia e que descreveria o indivíduo como um ser totalmente racional e incorruptível. Esse indivíduo faz o que se denomina de escolhas ótimas, em um ambiente bem especificado e bem definido, e suportado por modelos matemáticos e estatísticos que o levam sempre a escolhas ótimas e a uma maximização de resultados (MARCH e SIMON, 1966).

Por ser dinâmico e competitivo, o ambiente empresarial exige que as informações sejam tomadas de forma rápida, pois as oportunidades estão presentes no ambiente empresarial e devem ser reconhecidas e aproveitadas pelos administradores. É justamente neste ponto que a abordagem racional sofreu suas maiores críticas. March e Simon (1966) argumentam que o modelo racional serve apenas para os ambientes de certeza absoluta, nos quais se tem informações completas e conhecimento pleno, tanto do processo em si, como dos resultados a serem atingidos, além da certeza perfeita do próprio ambiente.

No entanto, é mais comum a tomada de decisão sob condições de variação nos graus de risco e de incerteza. Nesse contexto, compreende-se o risco como um estado de conhecimento em que o tomador de decisão está consciente dos problemas que enfrenta, mas não tem certeza a respeito dos resultados da aplicação do plano de ação. Já a incerteza é aquele estado em que não se conhece as probabilidades associadas a cada situação.

Herbert Simon, na década de 1950, fez uma leitura dessas críticas e dificuldades da abordagem racional e elaborou o estudo clássico que concluiu por uma racionalidade limitada dos indivíduos. Para ele, os indivíduos possuem, sim, certa racionalidade, porém esta é limitada e as decisões relacionadas estão condicionadas a possibilidades, e não a situações ótimas. Além disso, como o próprio nome diz, existe uma limitação clara da racionalidade humana, que se caracteriza por uma total impossibilidade de análise de todas as informações, alternativas e dimensões envolvidas no processo decisório, o que acarreta em uma inconsistência com a decisão ótima apregoada pela decisão ideal normativa (SIMON, 1965). Sendo assim, a racionalidade se reduz a uma aceitação do razoável, em que as alternativas são selecionadas pelo critério de encaixe em algum sistema de valores (BECKER et al., 1997).

Bethlem (1987) apresenta ainda vários modelos de processo decisório, como, por exemplo, o Modelo Militar, o Modelo de Pesquisa Operacional, o Modelo de Mintzberg e o Modelo da Decisão Racional, entre outros. A maioria desses modelos parte do pressuposto da racionalidade plena. Dessa forma, esses modelos, hoje em dia, em função da complexificação das relações comerciais, sociais e econômicas, parecem distantes da aplicabilidade geral. Em 
função disso, adotar-se-á neste estudo o Modelo Decisório de Racionalidade Limitada de Simon, para o qual tomar uma decisão compreende as fases evidenciadas na Figura 1.

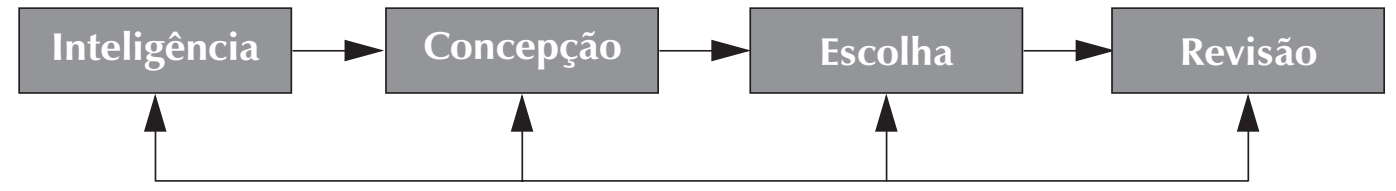

Fonte: Baseado em Simon (1977).

Figura 1 - Fases do Modelo do Processo Decisório de Simon.

De acordo com a Figura 1, a fase da inteligência refere-se à fase de investigação do ambiente para encontrar as condições que exigem uma decisão. A segunda fase preocupa-se com o desenvolvimento e análise de possíveis rumos de ação. A fase da escolha consiste na seleção de um determinado rumo de ação traçado na fase anterior. E, por fim, a revisão é a fase em que se faz a avaliação das escolhas, bem como dos rumos e das condições que levaram a tal decisão. Nesta fase, ocorre uma reavaliação do processo de tomada de decisão.

Seguindo essa concepção, Ackoff (1981) salienta que uma decisão passa por um ciclo de quatro etapas. A tomada de decisão - propriamente dita -, a implantação, a avaliação e a recomendação. Pois pouco adianta tomar uma decisão se ninguém ficar responsável por sua implantação e, se implantada, não for avaliada, e assim por diante, ficando evidente a necessidade de haver uma retroalimentação do processo (feedback).

O sucesso do administrador-empreendedor, portanto, está na sua capacidade de conviver com os riscos e sobreviver a eles. É esse um dos indivíduos que a todo instante toma decisões nas organizações. Dessa forma, compreende-se que o sucesso de um empreendimento está apoiado no comportamento e motivação do empreendedor aliado à tomada de decisão.

\section{Empreendedorismo}

Segundo Carland et al. (1984), um dos principais problemas nos estudos de empreendedorismo está na identificação do que é ser empreendedor, pois os autores sugerem que muitos estudos não distinguem adequadamente entre empreendedores e, principalmente, proprietários de pequenos negócios. Isso pode ocorrer em razão do empreendedorismo ser considerada uma área de estudo recente.

Há um consenso entre pesquisadores desse tema de que o empreendedorismo é um tema emergente e ainda não possui um conceitual teórico universal ou uma teoria consolidada (VESPER, 1980; FARREL, 1993; GIMENEZ e INÁCIO, 2002). Dessa forma, economistas, psicólogos e pesquisadores da área de marketing definem o empreendedor a partir de diferentes enfoques de suas áreas de pesquisa.

Percebem-se, ainda, duas correntes do pensamento que abordam o conceito de empreendedor de forma dicotômica: os economistas o associam à inovação; enquanto os comportamentalistas se concentram nos aspectos criativo e intuitivo. Logo, Schumpeter (1950) definiu o empreendedor como aquele que inova, contribuindo com o desenvolvimento econômico; e Filion (1999a) o descreveu como aquele indivíduo que imagina, desenvolve e realiza suas visões.

Portanto, por mais distintas que pareçam as definições de empreendedor registradas, elas possuem noções semelhantes, tais como: criatividade, inovação, organização, criação, dedicação e disposição para assumir riscos e aproveitar oportunidades.

Rev. Adm. UFSM, Santa Maria, v. I, n. 1, p. 153-170, jan./abr. 2008 
Embora criatividade seja definida pela habilidade de criar algo que ainda não exista, o caráter inovador é capaz de transformar aquilo que já existe em algo novo. A inovação é uma palavra relacionada à criatividade, pois não pode haver inovação sem criatividade. Nesse sentido, baseado na visão de Drucker (1987), que entende o empreendedorismo como um comportamento e não como um traço da personalidade, essas duas características são extremamente evidenciadas pelo autor no que se refere ao comportamento empreendedor. Mais do que isso, para o autor, o empreendedor vive o risco e a incerteza e motiva-se perante um maior grau de ocorrência desses no mercado.

Para Bernhoeft (1996), existem algumas motivações que levam o indivíduo a querer fazer algo diferente, que podem se apresentar de formas distintas. O autor chama atenção para o fato de que existem pessoas que apresentam características empreendedoras desde muito cedo. Inicialmente dentro do contexto familiar, depois na escola ou comunidade, vão assim desenvolvendo essa habilidade através de uma liderança que envolve e motiva os outros.

Filion (1999a, 1999b) e Carland, Carland e Hoy (1998) concordam que o empreendedorismo é o resultado tangível ou intangível de uma pessoa com habilidades criativas, sendo uma complexa função de experiências de vida, oportunidades, capacidades individuais e que, no seu exercício, está inerente a variável risco, tanto na vida como na carreira do empreendedor. Os mesmos autores concordam ainda que quantificar um atributo subjetivo é difícil, principalmente em função de não haver um teste ou instrumento que possa ser utilizado de forma universal.

Entretanto, o Carland Entrepreneurship Index (CEI) é um dos mais conhecidos instrumentos que se propõem a mensurar o potencial do empreendedor, tanto do ponto de vista acadêmico quanto empresarial, no âmbito dos Estados Unidos (CARLAND, 2001). Em sua avaliação, o autor desenvolveu uma escala de empreendedor em maior ou menor grau, considerando a presença de quatro elementos: traços de personalidade, que evidenciam necessidade de realização e criatividade; propensão à inovação; análise de riscos e postura estratégica.

O CEI apresenta três classificações para o indivíduo empreendedor, quais sejam: Macroempreendedor, o Empreendedor e o Microempreendedor, chegando-se a esta por meio da personalidade e das preferências do individuo. Porém, este instrumento não deve ser usado como ponto final, mas como um indicador que possa auxiliar o indivíduo a alcançar uma postura empreendedora.

Um Macroempreendedor verá seu negócio como um meio de mudar a indústria e tornar-se uma força dominante. Para ele, o sucesso é medido em termos do crescimento de seus negócios. Um Microempreendedor, por outro lado, cria um negócio, o qual nunca crescerá, mas que se torna referência em sua cidade ou comunidade. Ele vê sua iniciativa de negócio como fonte primária para a renda familiar ou para estabelecer emprego familiar, mas ele não espera nem aspira tornar-se nada além de seu negócio familiar. Enquanto o Macroempreendedor vê o seu negócio, geralmente, como o centro de seu universo, o Microempreendedor considera o negócio como uma fonte de renda, uma importante parte de sua vida, mas, certamente, não a principal delas.

Já o Empreendedor, além dos lucros, considera o crescimento essencial para o seu negócio, tendo um sucesso maior que os Microempreendedores, o que varia de empreendedor para empreendedor. Ao contrário dos Macroempreendedores que procuram abordagens totalmente inovativas, o Empreendedor busca melhorias para os produtos, serviços e procedimentos já estabelecidos, em vez de engenharem algo totalmente novo, pois essas melhorias possuem menos probabilidades de desestabilizar o caminho para o sucesso, que é tão importante para este tipo de empreendedor (CARLAND, 2001). 
Muitos autores, como McClelland (1972), Timmons (1978) e Hornaday (1982), afirmam que a orientação para o risco é a principal característica de um empreendedor. Porém, estudos acerca do perfil empreendedor encontraram outras características que permitem definir o empreendedor como alguém que usa a inovação, como seu instrumento específico, por meio do qual ele irá explorar uma mudança como oportunidade para um negócio ou serviço diferente.

Farrel (1993) aponta algumas outras características comportamentais que considera relevante em um empreendedor, a saber: conhecer muito bem o produto e o mercado; saber conduzir as pessoas e estimulá-las; manter o foco no produto e no cliente; ser estrategista.

O autor destaca ainda que os empreendedores devem estar focados em quais produtos e clientes a empresa pretende trabalhar, pois de todas as características de comportamento empreendedor, o foco duplo no cliente e no produto é o que melhor destaca a diferença entre empreendedores e gerentes profissionais.

Traçar uma descrição completa da personalidade do empreendedor não étarefa simples. Entretanto, algumas características de comportamento são consideradas comuns às pessoas empreendedoras. No Quadro 1, são apresentadas algumas características do empreendedor de sucesso, dentre muitas outras, freqüentemente citadas por vários autores.

\begin{tabular}{|l|c|c|c|c|c|c|}
\hline & $\begin{array}{c}\text { Schumpeter } \\
1950\end{array}$ & $\begin{array}{c}\text { McClelland } \\
1972\end{array}$ & $\begin{array}{c}\text { Timmons } \\
1978\end{array}$ & $\begin{array}{c}\text { Hornaday } \\
1982\end{array}$ & $\begin{array}{c}\text { Farrel } \\
1993\end{array}$ & $\begin{array}{c}\text { Carland } \\
2001\end{array}$ \\
\hline Inovação & $\mathrm{X}$ & $\mathrm{X}$ & & $\mathrm{X}$ & & $\mathrm{X}$ \\
\hline Liderança & & $\mathrm{X}$ & $\mathrm{X}$ & $\mathrm{X}$ & & $\mathrm{X}$ \\
\hline Analisar riscos & & $\mathrm{X}$ & & $\mathrm{X}$ & & \\
\hline Independência & & $\mathrm{X}$ & $\mathrm{X}$ & $\mathrm{X}$ & & \\
\hline $\begin{array}{l}\text { Orientação para } \\
\text { resultados/lucros }\end{array}$ & & & & & & $\mathrm{X}$ \\
\hline $\begin{array}{l}\text { Capacidade de } \\
\text { realização }\end{array}$ & & & & & $\mathrm{X}$ & $\mathrm{X}$ \\
\hline Ser estrategista & & & $\mathrm{X}$ & $\mathrm{X}$ & & \\
\hline Criatividade & & & & & & $\mathrm{X}$ \\
\hline Seguir exemplos & & & & & & \\
\hline
\end{tabular}

Fonte: Elaborado pela autora a partir de Schumpeter (1950); Fillion (1999); Farrel (1993) e Carland (2001).

Quadro 1 - Algumas características mais freqüentes atribuídas aos empreendedores de sucesso.

\section{Metodologia}

A pesquisa foi realizada em duas associações apícolas do Rio Grande do Sul, localizadas uma na Região Central e outra na Região Jacuí - Centro, cujas cidades são Santa Maria e Cachoeira do Sul, respectivamente. A escolha por essas associações deu-se pela sua proximidade geográfica em relação à pesquisadora e pela disponibilidade das empresas em participarem da pesquisa. Embora outras três associações pertencentes às referidas regiões também tenham sido contatadas, os presidentes não puderam atender à pesquisadora no período em que a pesquisa 
foi realizada. Ressalta-se que essas associações são filiadas à Federação de Apicultores do Rio Grande do Sul (FARGS), instituição que representa o setor apícola do Estado. Segundo cadastros de 2006, fornecidos pelo presidente da FARGS, há um total de 55 associações filiadas, sendo possível, mediante esses cadastros, identificar as demais associações do Estado.

Deve-se mencionar que a amostra a qual se aplicou esta pesquisa não é parte significante da população total. Porém, como o objetivo foi o de identificar o perfil empreendedor e o processo de tomada de decisão nas mesmas, exclusivamente, fica aqui a sugestão de se testarem os resultados e ampliá-los às demais associações filiadas à FARGS.

Trata-se de uma pesquisa de caráter exploratório. De acordo com Gil (2002), uma pesquisa exploratória envolve levantamento bibliográfico, entrevistas com pessoas que tiveram experiência práticas com o problema pesquisado e análise de exemplos que estimulem a compreensão da situação abordada.

Tomou-se como técnica a realização de questionários, dividindo-se o instrumento em duas partes: a primeira identifica o perfil empreendedor dos respondentes e a segunda, o seu processo decisório. O questionário foi aplicado aos presidentes de duas associações apícolas, objeto deste estudo.

Para identificar o perfil do empreendedor, utilizou-se a versão em português do instrumento de mensuração do potencial empreendedor intitulado Carland Entrepreneurship Index (CEI), desenvolvido por Carland (2001). O mesmo consiste de um questionário com trinta e três pares de frases afirmativas, no formato de escolha forçada. A maior ou menor presença dos elementos em um indivíduo (considerados pelo autor e citados na seção anterior) coloca-o, segundo a escala do CEI, entre os valores de 0 a 33 pontos, contidos em três faixas: de 0 a 15, Microempreendedor; de 16 a 25, Empreendedor e de 26 a 33 Macroempreendedor.

A segunda parte do instrumento, sobre o processo decisório, baseado em Macadar et al. (1997), foi composto de 10 questões, também fechadas e com resposta do tipo fechada única, em que cada questão corresponde a cada uma das variáveis do processo decisório no que tange às fases de Simon (1977) acrescidas da fase de implementação e avaliação discutidas por Ackoff (1981).

Dessa forma, após a coleta dos dados, procurou-se cruzar esses dados para identificar a relação entre o perfil empreendedor e o processo decisório.

\section{Resultados}

Primeiramente, a respeito do associativismo no agronegócio, adota-se o conceito de que o mesmo é um conjunto de práticas sociais desempenhadas pelos agricultores organizados, almejando benefícios comuns, os quais não conseguiriam atuando individualmente.

Barros (1994) destaca que as organizações associativas supõem as seguintes funções: tornar mais eficiente o esforço do grupo; aumentar o seu rendimento; diminuir o esforço de cada participante; dividir o trabalho ou as suas operações a serem realizadas; tornar um grupo mais integrado e estimular a interdependência dos indivíduos dentro da organização.

De acordo com Carland, Carland e Hoy (1992 e 1998), o indivíduo empreendedor se situa dentro de um continuum, no qual as pessoas podem ser identificadas como indivíduos mais ou menos empreendedores. Sendo assim, de acordo com a aplicação do CEl, ambos os presidentes podem ser considerados Empreendedores. $\mathrm{O}$, sendo que o presidente $\mathrm{B}$, cuja pontuação no CEl foi de 17, está muito próximo do Microempreendedor. O Presidente A, cujo CEl foi de 23, está mais próximo do Macroempreendedor (ver Figura 2). 


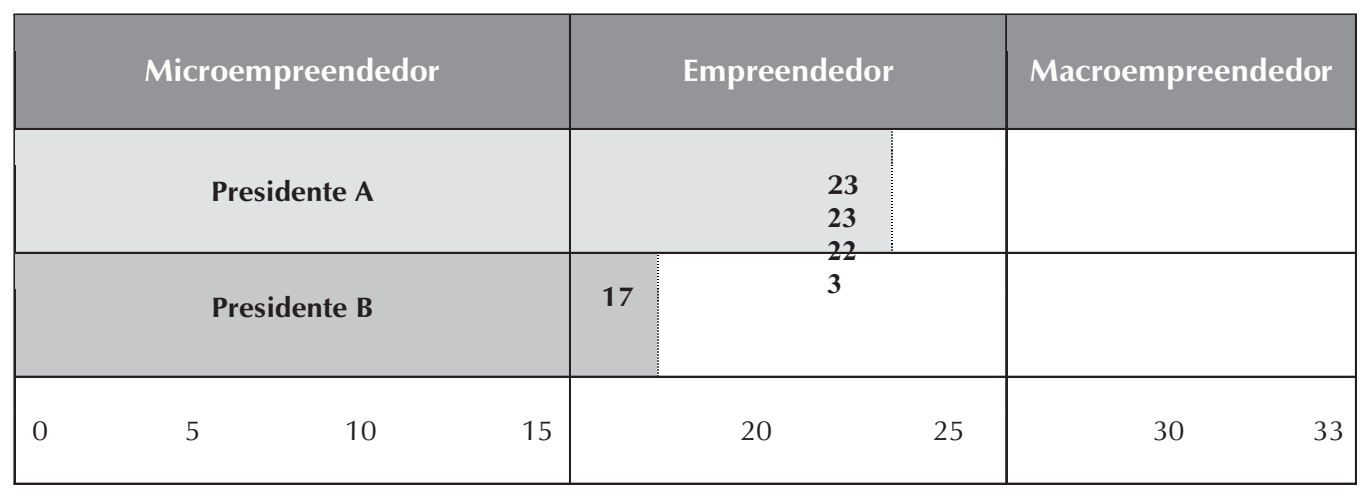

Fonte: Resultado da pesquisa.

Figura 02 - Utilização do CEI para classificação dos presidentes das associações.

Ambos os presidentes demonstram ainda outras características empreendedoras que podem ser observadas no Quadro 2, tais como: independência, aspecto evidenciado nas obras de McClelland (1972) e Hornaday (1982); seguir exemplos de pessoas de sucesso, de acordo com Timmons (1978) e Hornaday (1982); são criativos e buscam inovar, de acordo com Hornaday (1982) e Carland (2001) etc. Dentre aquelas características que ambos não apresentam está a capacidade de analisar riscos, conforme Carland (2001); e ser estrategista, de acordo com Farrel (1993) e Carland (2001); já que nem sempre os presidentes analisam as conseqüências antecipadamente, conforme evidenciado no Quadro 3.

\begin{tabular}{|l|c|c|}
\hline \multicolumn{1}{|c|}{$\begin{array}{c}\text { Características dos } \\
\text { empreendedores }\end{array}$} & $\begin{array}{c}\text { Presidente } \\
\text { A }\end{array}$ & Presidente B \\
\hline Inovação & X & X \\
\hline Liderança & X & X \\
\hline Analisar riscos & X & X \\
\hline Independência & X & X \\
\hline Orientação para resultados/lucro & X & X \\
\hline Capacidade de realização & - & - \\
\hline Ser estrategista & X & X \\
\hline Criatividade & X & X \\
\hline Seguir exemplos & & \\
\hline
\end{tabular}

Fonte: Resultado da pesquisa.

Quadro 2 - Características mais freqüentes encontradas nos presidentes

É relevante ressaltar que, enquanto presidentes, ambos desempenham atividades paralelas, nas quais também exercem a tomada de decisão, em posições de liderança, tanto no decorrer de suas vidas profissionais quanto em atuações junto à comunidade, pois ambos ocupam cargos de liderança em suas respectivas comunidades cristãs (membros da diretoria da igreja) e estão à frente de microempresas familiares. O presidente B exerce, ainda, cargos 
de destaque no contexto da apicultura estadual e nacional, atuando na FARGS e também na Confederação Brasileira de Apicultura (CBA), sendo responsável pelo Comitê de Desenvolvimento do Associativismo.

Em relação às atividades empreendedoras nas associações, salienta-se que o presidente A promoveu, em sua gestão (2006-2007), dois eventos técnicos de apicultura (Jornada Técnica 2006 e Workshop 2007). Além disso, em 2006, a sua associação também foi responsável pela realização do primeiro Jantar do Mel, com pratos feitos à base de mel, visando a promover e a incentivar o consumo do produto em seu município.

Sobre as atividades empreendedoras do presidente B, ressalta-se que o mesmo realizou dois cursos de apicultura, um em 2006 e outro em 2007, ao longo da sua gestão (2006-2007). Por meio desses dois cursos, 30 alunos foram capacitados para atuar na atividade apícola. Além disso, este presidente inaugurou a sala de envase da associação com Serviço de Inspeção Federal (SIF) na sede social da associação, onde o mel dos associados é envasado de acordo com as exigências do SIF e recebe em seu rótulo o selo de inspeção nacional. Além disso, esta associação dispõe de um apicultor que realiza a comercialização dos produtos dos associados nesta sede, possibilitando que a população, em geral, possa buscar informações sobre os produtos das abelhas e suas utilidades, além de atender aos apicultores da região. O presidente reativou também o serviço SOS Abelhas, no qual a comunidade pode solicitar auxílio por telefone dos apicultores para a retirada dos enxames de abelhas da zona urbana, removendo-os para a zona rural, com o objetivo de capturar os enxames, preservando a natureza e promovendo a segurança da população.

A respeito do processo decisório, tomou-se como referência as fases do modelo da racionalidade limitada de Simon (1977), acrescidas das fases de implementação e avaliação discutidas por Ackoff (1981).

Seguindo o Modelo de Simon (1977) quanto às fases do processo decisional, observouse, na fase da inteligência, no que tange à coleta e ao processamento de informações sobre o ambiente, com a finalidade de identificar oportunidades ou ameaças, que esta sempre foi exercida pelo presidente A, mas somente em algumas ocasiões pelo presidente $B$.

No que tange à fase de concepção, observou-se que as conseqüências das decisões do presidente A são sempre conhecidas antecipadamente, enquanto isto ocorre em apenas algumas ocasiões para o presidente B. Na fase de escolha, ambos os presidentes responderam que, ao tomarem uma decisão, selecionam as opções dentre as alternativas disponíveis e sempre analisam as suas conseqüências. Da mesma forma, quanto à fase de revisão ou feedback, o presidente A sempre volta atrás a fim de identificar outras alternativas antes de decidir, enquanto o presidente B somente algumas vezes faz essa revisão. Porém, após tomar uma decisão, ambos responderam que voltam atrás algumas vezes. Ao analisar ocasiões de implementação das decisões, ambos responderam que sempre executam ações para efetivar a solução. Já no que tange à avaliação da implementação da solução, o presidente A sempre a avalia, enquanto o presidente $\mathrm{B}$ a avalia somente algumas vezes.

Quanto ao sistema de tomada de decisão, se individual ou coletivo, observou-se que o presidente A, por vezes, o faz individualmente e, por vezes, coletivamente, enquanto o presidente B o faz predominantemente de forma coletiva. Entretanto, cabe destacar que ambos sempre consultam os familiares e sua equipe ao tomar uma decisão, o que ressalta o princípio do coletivismo presente em seus perfis.

Dessa forma, ao relacionar o modelo de Simon (1977) com o perfil empreendedor, tem-se o Quadro 3 a seguir. 


\begin{tabular}{|c|c|c|}
\hline $\begin{array}{l}\text { TIPO DE PERFIL } \\
\text { EMPREENDEDOR } \\
\text { PECISÓRIO }\end{array}$ & $\begin{array}{l}\text { PRESIDENTE B } \\
\text { EMPREENDEDOR }\end{array}$ & $\begin{array}{l}\text { PRESIDENTE A } \\
\text { EMPREENDEDOR }\end{array}$ \\
\hline INTELIGÊNCIA & $\begin{array}{l}\text { Algumas vezes coleta e processa } \\
\text { informações. }\end{array}$ & $\begin{array}{l}\text { Sempre coleta e processa } \\
\text { informações. }\end{array}$ \\
\hline CONCEPÇÃO & $\begin{array}{l}\text { Algumas vezes as conseqüências } \\
\text { são conhecidas antecipadamente. }\end{array}$ & Sempre são conhecidas. \\
\hline ESCOLHA & $\begin{array}{l}\text { Algumas vezes seleciona e analisa } \\
\text { dentre as alternativas. }\end{array}$ & Sempre seleciona e analisa. \\
\hline REVISÃO Feedback antes & $\begin{array}{l}\text { Algumas vezes volta atrás antes } \\
\text { de tomar uma decisão. }\end{array}$ & Sempre volta atrás. \\
\hline REVISÃO Feedback depois & $\begin{array}{l}\text { Algumas vezes volta atrás antes } \\
\text { de tomar uma decisão. }\end{array}$ & $\begin{array}{l}\text { Algumas vezes volta atrás antes } \\
\text { de tomar uma decisão. }\end{array}$ \\
\hline IMPLEMENTAÇÃO & $\begin{array}{l}\text { Sempre executa ações para } \\
\text { efetivar a solução. }\end{array}$ & $\begin{array}{l}\text { Sempre executa ações para } \\
\text { efetivar a solução. }\end{array}$ \\
\hline AVALIAÇÃO & Algumas vezes avalia. & Sempre avalia. \\
\hline $\begin{array}{l}\text { CARACTERÍSTICA } \\
\text { Individual/ Coletiva }\end{array}$ & $\begin{array}{l}\text { Toma decisões mais } \\
\text { coletivamente que } \\
\text { individualmente. }\end{array}$ & $\begin{array}{l}\text { Algumas vezes individualmente } \\
\text { e algumas vezes coletivamente. }\end{array}$ \\
\hline $\begin{array}{l}\text { CARACTERÍSTICA } \\
\text { Consulta família } \\
\end{array}$ & Sempre consulta a família. & Sempre consulta a família. \\
\hline $\begin{array}{l}\text { CARACTERÍSTICA } \\
\text { Consulta equipe }\end{array}$ & Sempre consulta a equipe. & Sempre consulta a equipe. \\
\hline
\end{tabular}

Fonte: Resultado do estudo.

Quadro 3 - Relação dos perfis dos presidentes das associações apícolas quanto ao empreendedorismo e ao processo decisório.

Dessa forma, apesar de se identificar os presidentes das associações de apicultores como indivíduos com potencial Empreendedor, o processo decisório sugere que nem todas as fases são planejadas de acordo com o Modelo de Simon (1977), seguindo todas as fases. Isso pode estar vinculado ao fato de que, algumas vezes, os presidentes acabam tendo que tomar decisões sozinhos por não haver associados dispostos a participar das decisões, pois, conforme ambos presidentes ressaltaram, existe pouco apoio, falta de participação e de comprometimento dos demais associados para com a associação, o que pode ser o ponto nevrálgico para o desenvolvimento das mesmas.

\section{Considerações finais}

A presente pesquisa alcançou seus objetivos, na medida em que oferece um quadro que permite observar a relação entre as variáveis do processo de decisão e do perfil empreendedor dos presidentes das duas associações apícolas em questão.

Considerando que, neste estudo, foram observadas organizações associativas, verificou-se que os perfis dos seus gestores corroboram com o princípio das organizações, baseadas no coletivismo. Observou-se também a presença de características empreendedoras nos gestores, tais como: inovação, criatividade, liderança, orientação para resultados/lucro e realização pessoal. 
Foi possível, ainda, identificar a presença das quatro fases do modelo de Simon (1977). No entanto, os presidentes apresentaram menos preocupação com o processo decisório na fase da escolha, pois eles nem sempre analisam as conseqüências das suas escolhas.

Embora o instrumento Carland Entrepreneurship Index (CEI), utilizado nesta pesquisa, distinga os indivíduos Macroempreendedores, Empreendedores e Microempreendedores, não se encontrou nenhum gestor com potencial Micro ou Macroempreendedor. Considerase que não seria interessante a presença do gestor com potencial Macroempreendedor em associações, em razão deste se preocupar mais com o sucesso pessoal do que com o bem-estar coletivo. O Macroempreendedor pode, ainda, concentrar o poder de decisão em benefício do seu próprio negócio, interferindo na tomada de decisão de forma tendenciosa. Assim, pode-se dizer que o mais desejável para as associações de apicultores seria se todos os gestores fossem Empreendedores, pois eles possuem objetivos mais ousados que os Microempreendedores, ou seja, eles concentram seus esforços para o crescimento da associação, como acontece nas associações de Santa Maria e Cachoeira do Sul, em que os seus gestores são Empreendedores.

Ressalta-se ainda que, embora os dois presidentes sejam microempresários e tenham sido identificados com potencial Empreendedor, é possível perceber que o presidente A, o qual está mais próximo da pontuação do Macroempreendedor, é o presidente que demonstra estar mais ciente da importância do processo de gestão e de tomada de decisão. A pontuação do seu potencial Empreendedor mais próximo ao Macroempreendedor sugere que este presidente possa ter como objetivo o seu crescimento individual ante ao crescimento coletivo. De forma contrária, o presidente B demonstra estar menos preocupado com o processo de tomada de decisão da associação, e nem sempre avalia as decisões que estão sendo tomadas, embora busque tomar as decisões de forma mais coletiva do que individual, demonstrando uma preocupação maior com o sucesso do empreendimento coletivo do que com o seu próprio sucesso.

Dessa forma, seria interessante se um número maior de associações de apicultores conseguisse atuar de forma empreendedora, com vistas à produção dos demais produtos das abelhas ou de mel orgânico, por exemplo. No entanto, para isso ocorrer, o comportamento dos demais associados em relação à associação também precisaria mudar, principalmente no que tange à pouca participação deles nas atividades das associações. Assim, esses aspectos refletem a realidade das associações estudadas e trabalhar esses elementos seria tornar a apicultura mais profissional, rumo ao empreendedorismo.

Sugere-se que sejam feitos estudos futuros, procurando analisar a fundo quais os principais motivos que dificultam o processo de tomada de decisão dos presidentes das associações de apicultores e também a ampliação do estudo, considerando as demais associações apícolas cadastradas junto à FARGS, a fim de possibilitar a realização de análises complementares.

Percebe-se que uma qualidade e ao mesmo tempo uma limitação do estudo é o seu ineditismo. Qualidade por permitir mais conhecimento acerca do associativismo apícola e servir como estímulo para outros estudos na área. Limitação em razão da utilização da versão em português do instrumento Carland Entrepreneurship Index (CEI) ter sido validada por alunos de graduação e pós-graduação em administração de empresas e por proprietários-gerentes de empresas residentes em incubadoras tecnológicas do Estado do Paraná. Além disso, a aplicação do instrumento é inédita em organizações de natureza coletiva, em que a percepção da gestão como algo importante começou a ocorrer somente a partir dos anos 1980 e nas associações apícolas muito depois. 


\section{Referências bibliográficas}

ACKOFF, R. L. Planejamento empresarial. Rio de Janeiro: Livros Técnicos Científicos, 1981.

\section{ANDREWS, K. R. The concept of corporate} strategy. Homewood: Irwin, 1971.

BARROS, E. V. Princípios de ciências sociais para a extensão rural. Viçosa: UFV, 1994.

BECKER, J. L. et al. Informação e decisão: sistemas de apoio e seu impacto. Porto Alegre: Ortiz, 1997, 214 p.

BETHLEM, A. de S. Modelos de processo Decisório. Revista de Administração, São Paulo, v. 22, n. 3, p. 27-39, jul./set. 1987.

BERNHOEFT, R. Como tornar-se empreendedor em qualquer idade. São Paulo: Nobel, 1996.

CARLAND, J. W.; HOY, F. S.; BOULTON, W. R.; CARLAND, J. A. Differentiating entrepreneurs from small business owners: a conceptualization. Academy of Management Review, Mississippi, v. 9, n. 3, p. 354-359, Apr. 1984.

CARLAND, J. W.; CARLAND, J. A.; HOY, F. S. An entrepreneurship index: an empirical validation. Massachusetts: INSEAD, 1992.

CARLAND, J. W.; CARLAND, J. A.; HOY, F. S. Who is an entrepreneur? Is a question worth asking? American Journal of Small Business, Baltimore, v. 12, n. 4, p. 33-39, Apr. 1998.

CARLAND, J. W. Carland Entrepreneurship Index - Report. Business Development Test, Inc. North California, 2001. Disponível em: < http:// www.biztest.com>. Acesso em: 21 jan. 2007.

DRUCKER, P. Inovação e espírito empreendedor (entrepreneurship). 3 ed. São Paulo: Pioneira, 1987.

FARREL, L. C. Entrepreneurship: fundamentos das organizações empreendedoras. São Paulo: Atlas, 1993.

FILION, L. J. Empreendedorismo: empreendedores e proprietários-gerentes de pequenos negócios. Revista de Administração, São Paulo, v. 34, n. 2, p. 5-28, abr./jun. 1999a.
Diferenças entre sistemas gerenciais de empreendedores e operadores de pequenos negócios. Revista de Administração de Empresas, São Paulo, v. 39, n. 4, p. 6-20, out./dez. 1999b.

GIL, A. C. Técnicas de pesquisa em economia e elaboração de monografias. 4. ed. São Paulo: Atlas, 2002.

GIMENEZ, F. A. P.; INÁCIO, Jr. E. Potencial empreendedor: um instrumento para mensuração. In: SIMPÓSIO DE GESTÃO DA INOVAÇÃO TECNOLÓGICA, 22., 2002, Salvador. Anais... Salvador: ANPAD, 2002. p. 1-14.

HORNADAY, J. A. Research about living entrepreneurs. Englewood Cliffs, NJ: Prentice Hall, 1982.

MACADAR, M. et al. A concepção e validação de um conjunto de instrumentos quanti-quali para estudar o processo decisório segundo as culturas nacionais e os níveis de experiência decisória. In: ENAMPAD, 21., 1997, Angra dos Reis. Anais... Angra dos Reis: ENAMPAD/ AMPAD, 1997. p.1-149.

MARCH, J. G.; SIMON, H. A. Limites cognitivos da racionalidade. In: MARCH, J. G.; SIMON, $\mathrm{H}$. A teoria das organizações. Rio de Janeiro: Fundação Getúlio Vargas, 1966. p. 192-220. McCLELLAND, D. C. A sociedade competitiva: realização e progresso social. Rio de Janeiro: Expressão e Cultura, 1972.

SIMON, H. A. Comportamento administrativo: estudo dos processos decisórios nas organizações administrativas. Rio de Janeiro: FGV, 1965.

Models of discovery. Dordrecht, Holland: D. Reidel, 1977.

SCHUMPETER, J. A. Capitalism, socialism and democracy. 3. ed. New York: Harper \& Row, 1950. 
TIMMONS, J. A. Characteristics and role demands of entrepreneurship. American Journal of Small Business, Baltimore, v. 3, n. 1, p. 5-17, 1978.

VESPER, K. New venture strategies. Englewood Cliffs, NJ: Prentice Hall, 1980. 